\title{
UNA CONFRONTACIÓN POLÍTICO-RETÓRICA: LOS DISCURSOS DE FILIPO, PERSEO Y DEMETRIO EN TITO LIVIO $(40,5-16)^{1}$
}

\author{
A POLITICAL-RHETORICAL CONFRONTATION: \\ THE SPEECHES OF PHILIP, PERSEUS AND DEMETRIUS \\ IN TITUS LIVIUS $(40,5-16)$
}

\author{
JUAN LORENZO LORENZO \\ Universidad Complutense \\ julorenz@ucm.es
}

DOI: $10.1387 /$ veleia.14977

\begin{abstract}
Resumen: En los múltiples trabajos acerca de la relación entre retórica e historiografía son objeto de especial atención las alocuciones pronunciadas por destacados personajes políticos y las arengas militares, clasificadas entre los discursos de naturaleza deliberativa. Sin embargo, apenas han despertado el interés de los investigadores los escasos discursos pertenecientes al género judicial. En este trabajo estudio, desde el punto de vista de la preceptiva retórica, los discursos de acusación y defensa pronunciados por Perseo y Demetrio, única muestra de oratoria forense en la monumental obra del historiador latino Tito Livio.
\end{abstract}

Palabras clave: retórica, historiografía, discurso judicial, actio.

Abstract: In many works dealing with the relationship between rhetoric and historiography, special attention has been paid to speeches delivered by prominent political figures and also to military harangues, a type of speech included among those of a deliberative nature. However, the few speeches belonging to the judicial genre have hardly attracted the interest of researchers, and this is why this study focuses on one of them from the point of view of prescriptive rhetoric, i.e. the prosecution and defence speeches delivered by Perseus and Demetrius, which is the only sample of forensic oratory in the monumental work of the Roman historian Livy.

Keywords: rhetoric, historiography, judicial discourse, actio.

Recibido: 20-11-2014

Informado: 09-01-2015

Definitivo: 11-02-2015

Son muchos los trabajos aparecidos en los últimos años en los que se llama la atención sobre las conexiones que hay entre el orador y el historiador (Marincola 2007, 119) y, por extensión, entre la oratoria y la historiografía: «Pour les spécialistes de l'Antiquité, parler d'histoire sans parler de rhétorique est imposible» (Cogitore et Ferretti 2014, 2). Esta idea parte ya de Cicerón, que define

1 Trabajo realizado en el marco del Proyecto de Investigación (Ref. FFI2011-29055), adscrito a la Uni- versidad de Salamanca, financiado por el Ministerio de Economía y Competitividad. 
la historia como opus oratorium (leg. 1, 5, 21), con las precisiones que cabe hacer a esta definición (Hinojo 1985, 191-198; Sánchez Salor 2008, 125-126). La historiografía latina ha de verse, pues, como un género literario más, y a la producción comprendida en este epígrafe se le puede aplicar la consideración de una obra oratoria sobre acontecimientos históricos. Una prueba de esta manera de ver la historiografía la constituye el hecho de que los grandes historiadores latinos - exornatores rerum - construyan sus relatos conforme a las normas fijadas en la retórica, y es, precisamente, la aplicación de los preceptos retóricos a la narración de los hechos lo que eleva la historiografía a la categoría de género literario. Entre nosotros contamos con excelentes estudios, realizados por magníficos y rigurosos investigadores, que confirman la estrecha relación existente entre la técnica retórica y el género literario de la historiografía, afinidad que se manifiesta en múltiples aspectos. Desde títulos generales de volúmenes completos sobre esta cuestión, como el editado por Woodman (Woodman 1988), hasta trabajos que abordan puntos concretos de la misma, la bibliografía disponible es muy abundante.

Una lectura pausada y crítica de la obra de T. Livio pone ante los ojos del lector el artístico resultado de la aplicación de técnicas retóricas en la manera de tratar los acontecimientos históricos, perceptible sobre todo cuando la conservación de la fuente permite comparar las dos versiones de un mismo hecho y comprobar la transformación literaria que hace Livio del material histórico proporcionado por la fuente. Una muestra de las más claras, sin duda, es la reelaboración que hace Livio $(7,9-10)$ del relato de Claudio Cuadrigario ${ }^{2}$ sobre el enfrentamiento entre un galo y el romano Manlio Torcuato. Por la comparación de los dos relatos, se comprueba que Livio no se apartó ni un momento del modelo, pero la reelaboración artística tiene su sello inconfundible (Marouzeau 1921, 160). No merece la pena insistir en que el historiador romano recibió en su juventud una sólida formación retórica y, según sus biógrafos, profesó una gran admiración intelectual por la oratoria ciceroniana (Girod 1979, 61-70). Son muchos los testimonios, algunos antiguos, que afirman la formación retórica de Livio y declaran que, «si no llegó a ser un consumado maestro de retórica, fue un apasionado cultivador de la misma» (Cocchia 1980, 12). Séneca el Viejo (suas. 6, 21), en alusión a la costumbre de los historiadores de añadir al relato de la muerte de los grandes hombres un resumen de su vida, afirma que T. Livio desarrolló generosamente la práctica de los elogios fúnebres, según las reglas del arte. Tácito (ann. 4, 34, 12) destaca su brillante elocuencia (Titus Liuius, eloquentiae ac fidei praeclarus), y Quintiliano (inst. 8, 1, 3), que le reconoce una extraordinaria facundia (mirae facundiae uir), elogia, sobre todo, su elocuencia y la facilidad oratoria en los "discursos» que inserta en su relato histórico, de los que destaca la correspondencia que hay entre las palabras pronunciadas, el personaje que las pronuncia y las circunstancias que rodean al hecho narrado. ${ }^{3}$

De los aspectos seleccionados por quienes se acercan al estudio de las relaciones entre retórica e historiografía, ocupa un lugar primordial la inserción de las palabras pronunciadas en diferentes escenarios por personajes políticos o por jefes militares, adorno indispensable de la historiografía clásica siguiendo una tradición que arranca en el propio Heródoto, el padre de la historia (Ullmann 1927). Mientras que a un historiador moderno se le exige que reproduzca con fidelidad las palabras de los protagonistas de los hechos narrados, los historiadores clásicos, por el contrario, ante la imposibilidad de recordar y reproducir con exactitud las palabras de los distintos personajes, op-

2 Fragmento transmitido por Aulo Gelio: Quadrig. frg. Gell. 9. 13, 7-19.
3 Quint, inst. 10, 1, 101: ... Titum Liuium, cum in narrando mirae iucunditatis clarissimique candoris, tum in contionibus supra quam enarrari potest eloquentem, ita quae dicuntur omnia cum rebus tum personis accommodata sunt. 
tan por ser ellos los «oradores» e incorporan en sus obras los discursos que ellos mismos han compuesto, a modo de una convención o ejercicio retórico, por lo que el lector se encuentra a cada paso con la reproducción de las palabras presumiblemente pronunciadas por alguno de los protagonistas, inserciones que, según la opinión más extendida, funcionan como adorno de un texto literario plagado de tópicos más o menos recurrentes, en vez de un documento histórico que reproduzca, con mayor o menor fidelidad, "la verdad de lo sucedido o lo pronunciado» (Villalba 2008, 341). La habilidad del historiador clásico se manifiesta en la capacidad de encajar en tales discursos elementos casi idénticos que pueden combinarse de múltiples maneras, como sucede con las leyes sobre las que se construye la acusación y la defensa, cuyo resultado son piezas literarias siempre diferentes (van Mal-Maeder 2007, 24). La historiografía antigua era vista como un género literario de aparato antes que como historia más o menos científica y más que la veracidad de lo dicho importa que el relato sea verosímil. A partir de la vaga noticia de que un determinado personaje hizo uso de la palabra, el historiador construye un discurso completo en el que incluye un conjunto de lugares comunes fijados por la retórica para esta clase de «hipotéticos parlamentos» (Moreno 2008, 319). Un número considerable de los frecuentes ejemplos de tales ficciones literarias construidas por Livio parten de una menguada base real y de una noticia introducida, de manera imprecisa, por medio de formas verbales propias para la difusión de rumores. Es lo que sucede con la arenga de Aníbal: contione inde aduocata ita apud eos locutus fertur (21, 43, 2-ss.) o con la reproducción de las palabras de Q. Fabio Máximo: Q. Fabius Maximus sic eum proficiscentem adlocutus fertur (22, 39, 2-ss.).

A pesar de que no hay discursos puros (judiciales, deliberativos, demostrativos), en el sentido de que los bordes entre ellos son oscuros y no están marcados con claridad (Cantó-Codoñer-Ramos Guerreira 1987, 23), sin embargo, por lo que se refiere al tipo de discurso en el que encasillar las alocuciones de embajada y las arengas militares, la opinión más extendida es la de quienes las consideran de naturaleza deliberativa, pues estos discursos surgen por su relación con acciones llevadas a cabo por individuos o grupos de personas (Marincola 2007, 127).

La producción literaria de los historiadores grecolatinos constituye una excelente muestra de esta práctica y, en el ámbito de la historiografía latina, ocupa una posición destacada la obra de Tito Livio, auténtica colección de tales piezas oratorias (Walsh 1963, 219-244). Abundan, sobre todo en los primeros libros, los discursos pronunciados en el Senado o en la Asamblea por magistrados o por emisarios llegados de distintas ciudades, seguidos, en orden de frecuencia, por las arengas que los generales dirigían a los soldados antes, durante o después del combate (Burk 1971, 41). Las numerosísimas alocuciones - hasta 407- que salpican la extensa obra conservada de Livio se distribuyen en cuatro bloques, de acuerdo con su contenido: discursos sobre política internacional, política interna, asuntos militares y discursos de naturaleza privada y personal (Gries 1949, 128); escasean, por el contrario, las muestras de discurso forense en la historiografía latina y, en toda la obra de Tito Livio, se conoce solo un conjunto de discursos clasificables dentro del genus iudiciale: las intervenciones de Perseo y Demetrio en presencia de su padre en la Corte de Macedonia, intervenciones precedidas por las palabras de Filipo, que, a su condición de padre, une el difícil papel de juez (Walsh, 1963, 226; Marincola 2007, 128). Prueba de la singularidad de esta muestra de oratoria judicial es que, en los muchos estudios sobre las arengas civiles o militares que incorporan, a modo de apéndice, una relación de todas las alocuciones localizadas en la producción historiográfica latina y, por ende, en la obra de Tito Livio, en ninguna de estas relaciones figura el fragmento objeto de estudio (Iglesias Zoido 2008, 557). La singularidad del fragmento, por desarrollarse en él un contenido de naturaleza forense y no deliberativa, y el hecho de que, hasta el momento, no haya sido objeto de un estudio detallado fueron las razones que me movieron a fijarme en él y tomarlo como soporte de un análisis que no tiene otra pretensión que la de constituir 
un eslabón más en la muy larga cadena de trabajos sobre la relación de la retórica y la historiografía y sobre la obra histórica de Tito Livio. Creo que, por ello, merecía la pena prestar atención a esta muestra, la única en Livio, de oratoria judicial.

\section{Discurso de Filipo}

Con todo, es preciso hacer una puntualización a la denominada por mí «singularidad del fragmento». Frente a quienes se inclinan por considerar la intervención de Filipo y las de sus hijos como un conjunto de tres piezas menores de naturaleza judicial, mi opinión es que sólo dos de ellas merecen la consideración de discursos judiciales — el de la acusación de Perseo contra Demetrio y el de la refutación, por parte del propio Demetrio, de las inculpaciones de Perseo-. Por el contrario, creo que debe dejarse fuera del bloque de discursos forenses la intervención preliminar de Filipo. No faltan estudiosos que afirman, sin concretar más, que en el libro 40 de $A V C$ hay, extrańamente, un agrupamiento de discursos de tipo forense, pertenecientes al genus iudiciale y, para disipar cualquier duda que pudiera haber sobre la adscripción de estas intervenciones al tipo de discurso judicial, especifican, de manera expresa, el número. Algunos, como Briscoe, hablan de tres discursos, sin especificar más, pronunciados en la Corte de Macedonia, en referencia a los parlamentos de Filipo, de Perseo y de Demetrio, como discursos clasificables en el tipo judicial: «these are three orations made at the court of Macedonia (chs. 8-15)» (Briscoe 2008, 17).

Creo, sin embargo, que las palabras preliminares de Filipo deben interpretarse desde los principios teóricos de la oratoria deliberativa, no de la forense. Se puede objetar que las palabras de Filipo no tienen intención persuasiva, sino de reproche, y que, desde el punto de vista del tiempo, hacen referencia al pasado, tiempo asociado al discurso judicial, y no al futuro, el tiempo propio de las intervenciones deliberativas. Esto es así, pero del texto de Livio se desprende que, en el pasado, Filipo, ante «los gestos» nada fraternales que veía en sus hijos y las «expresiones» hostiles que escuchaba, se habría dirigido presumiblemente a ellos con palabras edificantes que tendrían por objeto eliminar los rencores y disipar los recelos entre ellos:

«La verdad es que hace ya tiempo que temía esta tempestad que se avecinaba, cuando veía los gestos nada fraternales entre vosotros y escuchaba determinadas expresiones. Pero de tiempo en tiempo concebía la esperanza de que vuestros rencores podrían consumirse por sí solos y vuestros recelos podrían disiparse. [...] ¡Cuántas veces no maldije en vuestra presencia los ejemplos de desavenencias entre hermanos y llamé la atención sobre sus terribles consecuencias, acarreando su propia ruina y la de su estirpe, sus casas y sus reinos» $(40,8,8-12)^{4}$.

Los reproches y las recomendaciones de Filipo parecen hallarse más cerca del «discurso» deliberativo que del judicial. Detrás de sus palabras el lector puede imaginar un escenario real, situado en el pasado, en donde aparecería Filipo reprendiendo a sus hijos e instándoles a abandonar el camino de la discordia y dejar a un lado las desavenencias. Las supuestas palabras de entonces pronunciadas por Filipo, con propósito persuasivo, iban envueltas por los dos sentimientos característicos de la oratoria deliberativa (Lausberg 1966,205$)^{5}$, a los que se alude expresamente en el pasaje acotado: el temor (Iam pridem quidem hanc procellam imminentem timebam...) $(40,8,8)$ y la esperanza (Sed interdum spes animum subibat ...) $(40,8,9)$.

4 Las traducciones de los textos citados de T. Livio son de Villar Vidal, J.A., Madrid, BCG, 1993.
5 «Los afectos principales del genus deliberatiuum son la spes y el metus». 
Pero la presencia de los sentimientos de «temor» y «esperanza» no es el único indicio que apunta a un discurso deliberativo; hay un recurso más, y de más peso, que refuerza mi creencia de que la intervención de Filipo ha de considerarse una muestra de oratoria deliberativa, no judicial. En la imaginada intervención de Filipo, éste buscaría disuadir a los hijos de que continuaran por el camino del enfrentamiento, que tendría, inevitablemente, funestas consecuencias, y trataría de persuadirlos para que volvieran a la senda de la concordia mediante la presentación de varios exempla, recurso específico de los parlamentos deliberativos. En el fragmento acotado, Filipo, por boca de Livio, presenta a sus hijos ejemplos de parejas de hermanos, ilustrativos de una y otra forma de comportarse y con una y otra finalidad: exempla discordiarum fraternarum y meliora quoque exempla $(40,8,11-12)$. Como muestra de una conducta edificante y de concordia durante los primeros siglos de la etapa monárquica menciona el ejemplo de los dos reyes de Lacedemonia, conducta que degeneró y causó la ruina de aquel mismo Estado cuando se implantó la costumbre de arrebatar por la fuerza el poder y convertirlo en un poder absoluto. Refuerza este ejemplo con el de los hermanos Éumenes y Átalo que, gracias al entendimiento y a la armonía que había entre ellos, consiguieron, a partir de unos orígenes modestos, igualar su poder con el del propio Filipo y el de otros reyes contemporáneos. En la práctica de utilizar «ejemplos» sigue Livio a Polibio, su fuente directa de información, en lo referente a los acontecimientos de Grecia, que Livio somete a un proceso de reelaboración no sólo en lo que respecta al ámbito estilístico y literario sino también a la concepción misma de la historia. Livio da a la historia científica y universal de Polibio una dimensión nacionalista, digna del poder de Roma (Pianezzola 1969, 16). Debido a la impronta conservadora de la sociedad romana, el moralismo encontraba el terreno más fecundo en el género de la Historia que, por su carácter moralizante, ponía ante los ojos una variada galería de uiri que encarnaban las diversas virtudes romanas y servían de exempla en los que podían mirarse los ciudadanos (Pianezzola 1969, 51). La reelaboración artística que hace Livio del texto de Polibio sobre los acontecimientos referidos a la caída de la Corte de Macedonia le brinda la oportunidad de demostrar su formación y habilidad retóricas y, como consecuencia del conocimiento de esta técnica, su capacidad oratoria y dramática. El interés del discurso de Filipo nace del hecho de que, en este caso, contamos con el texto fragmentario de Polibio $^{6}$ que sirvió de fuente de información a Livio (Chaplin 2000, 80-81) y que éste siguió de cerca, con la adición de ejemplos romanos:

«Debéis leer no sólo los mitos, las tragedias y las historias, sino, además, ponderar sus argumentos. $\mathrm{Y}$ en todas estas obras se puede ver cómo aquellos hermanos que en rencillas y en enemistades [...] no sólo se destruyen a sí mismos, sino que arruinan totalmente su vida, sus hijos y sus ciudades. [...] No me negaréis que muchas veces puse a vuestra consideración el caso de los reyes de Lacedemonia: os explicaba que, mientras obedecieron a los éforos tal como se obedece a un padre, y ambos se toleraron mutuamente en el reino, conservaron para su patria la hegemonía sobre todos los griegos. [...] Y, finalmente, os he expuesto, a guisa de ejemplo, y os he señalado con toda claridad el caso de Éumenes y de Átalo: estos heredaron un imperio pequeño, cogido casi al azar, y lo han acrecido hasta el punto de que ahora no es inferior a ningún otro. Y lo han conseguido no por otra cosa que por su concordia y armonía y por su capacidad de observar un aprecio mutuo...» (Plb. Fr. 23, 11, 1-8) ${ }^{7}$.

6 No se ha de olvidar que Polibio, en la crítica que hace a Filarco, se muestra contrario a la inserción indiscriminada de discursos inventados en las obras historiográficas: "Conviene que no invente discursos en cualquier oportunidad...» (Plb. Historias 2, 56, 10).
7 La traducción es de Balasch Recort, M., Madrid, BCG, 1983. 
La comparación de las dos versiones ayuda a comprender la distinta concepción de la historia que tienen uno y otro escritor y explica algunas de las transformaciones realizadas en $A V C$, de las que, en el caso concreto que nos ocupa, llama la atención que Livio haya ańadido a los ejemplos de concordia y armonía de Polibio tres parejas de ejemplos de filial concordia entre hermanos tomados de la historia de Roma (Luce 1977, 109, n. 55): la de Tito y Lucio Quincio, la de Publio y Lucio Escipión y la de su padre y su tío:

Ne Romanis quidem exemplis abstinui, quae aut uisa aut audita habebam, T. et L. Quinctiorum, qui bellum mecum gesserunt, P. et L. Scipionum, qui Antiochum deuicerunt, patris patruique eorum, quorum perpetuam uitae concordiam mors quoque miscuit $(40,8,15)$.

Hay que reconocer, sin embargo, que, a pesar del origen nacional de estas tres parejas de ejemplos, Filipo no logra persuadir a su audiencia de dos:

«and the brother's rivalry leads to Demetrius' death, Philip's miserable old age, and Perseus' downfall at the hands of the Romans. Philip's inhability to persuade his sons prepares the way for Perseus' failures to learn from the past when he himself becomes king» (Chaplin 2000, 81).

Resumiendo, en la intervención de Filipo se aprecia más de una característica del discurso deliberativo, como es la alusión a los sentimientos de esperanza/miedo y la utilización de ejemplos, elemento apropiado para la deliberación, no para la demostración del género judicial, que prefiere recurrir al entimema o silogismo retórico (Velasco 2000, 48). Creo, en conclusión, que la alocución de Filipo, la primera de las tres que constituyen el bloque narrativo objeto de estudio, ha de separarse de los discursos de Perseo y de Demetrio e incluirse en la modalidad de discurso deliberativo, no entre los judiciales.

A partir de las palabras vaticinadoras de Filipo se puede intuir ya el drama que se avecina cuyo desenlace final empieza con la muerte de Demetrio. La tensión entre los hermanos, iniciada mucho antes, fruto de sospechas, indagaciones secretas, conspiraciones, celos, traiciones e insinuaciones maliciosas, va creciendo poco a poco hasta alcanzar el grado más alto cuando Perseo, al comprobar la popularidad de la que goza su hermano entre la población de Macedonia y el crédito que tiene entre los romanos, pensó que no le quedaba otro camino para llegar al poder que recurrir al crimen. La ruptura de la creciente tensión se produce el día de la purificación del ejército, fecha en la que suceden los hechos conducentes al proceso judicial del que vamos a ser testigos de excepción llevados por la habilidad retórica de Livio. El marco escénico se desdobla en dos momentos del mismo drama, correspondientes a dos fechas sucesivas (hesterno die: 40, 9, 10; 40, 10, 7 y Postero die. $40,8,1)$ que se oponen entre sí por la presencia de rasgos antitéticos: la noche de la primera jornada: cum uocatus ad cenam ab Demetrio Perseus negasset: 40, 7, 1 ;...nocte cum armatis domum ad interficiendum me uenit: 40, 8, 2) frente al dia de la jornada siguiente (Postero die...: 40, 8, 1). La oposición dramática no se manifiesta sólo en la antítesis noche/día sino que perdura en lo que se refiere a los rasgos caracterizadores de estos dos segmentos temporales, a cada uno de los cuales va asociado un tono y una actitud distintos. En la primera jornada sobresale el movimiento, la algarabía, las continuas idas y venidas y, en definitiva, el tono festivo (la hilaritas), mientras que el escenario de la jornada siguiente (Posterus dies) se caracteriza por la quietud, el silencio, la turbación y la tristeza (maestitia), aparte de que se ha producido un cambio de escenario: el palacio real.

Fiel a la costumbre de crear escenas visuales y relatar los hechos, como si se tratara de una representación teatral, Livio empieza por presentar y describir el escenario que va a servir de marco 
al inminente proceso judicial. Los preparativos previos a la celebración del juicio son los habituales en «espectáculos» semejantes, empezando por la presentación de los actores necesarios en este tipo de procesos: el acusador, el acusado y el juez. Cuando Perseo supo, por un delator, que Demetrio acudía a su residencia acompañado por cuatro jóvenes armados con intención de asesinarlo, ordenó cerrar las puertas e impedirle la entrada. Al día siguiente entró en el palacio real y se presentó ante su padre con intención de denunciar al hermano; permaneció en su presencia firme, con la expresión alterada, en silencio y alejado de él. La tensión dramática del momento y la preparación del escenario queda reflejada por la rapidez con la que Livio enumera las sucesivas circunstancias que rodean la presentación y la actitud delante de su padre: regiam ingressus perturbato uoltu in conspectu patris tacitus procul constitit $(40,8,1)$. Interrogado por Filipo acerca de cuál era el motivo de semejante turbación, le confesó lo que había de ser el primer punto de su acusación (crimen) contra Demetrio: «Anoche [Demetrio] vino a mi casa con hombres armados para matarme» $(40,8,2-3)$.

La acusación ya está hecha. La defensa - la autodefensa - la asume el propio acusado, y el encargado de emitir el veredicto es Filipo, padre y juez al mismo tiempo. La escena se completa con la citación de Demetrio y la convocatoria de dos amigos de Filipo, personas prudentes e imparciales, para que actúen como consejeros del «juez».

La tensión de la espera va en aumento: el rey camina solo de un lado para otro, el hijo permanece de pie y a distancia. A la llegada de los amigos, se retiran todos al interior del palacio, acompańado el rey por miembros de su guardia personal, y cada uno de sus hijos por tres escoltas, desarmados. Una vez constituido el tribunal, el rey empieza su parlamento con la confesión del infortunio de un padre que, sin dejar de ser padre, toma asiento como juez, y abre la sesión:

"sedeo», inquit, "miserrimus pater iudex inter duos filios, accusatorem parricidii et reum, aut conficti aut admissi criminis labem apud meos inuenturus» $(40,8,7)$.

La viva descripción del escenario atrapa al lector, convertido ya en espectador. El lector parece estar asistiendo, en directo, a los acontecimientos descritos por el historiador (Feldherr 1963, 4-18).

A pesar de que Perseo declara que no actúa como acusador en una causa forense ni argumenta para sacar conclusiones a partir de indicios dudosos (Nibil ego, tamquam accusator, criminose nec dubia argumentis conligendo ago: 40, 9, 13), sin embargo sus palabras de acusación y las de autodefensa de Demetrio han de examinarse a la luz de la teoría retórica concerniente a la oratoria judicial y, si bien es creíble que el origen de la rivalidad entre ellos pudo haber tenido una cierta base histórica, es difícil sostener la misma historicidad para los discursos de Perseo y de Demetrio. Han de considerarse, como hemos dicho más arriba, ficciones literarias que reproducen lo que, presumiblemente, dijeron o, mejor, debieron de decir cada uno de ellos en las circunstancias indicadas.

Por el lugar donde se desarrolla el juicio, no se puede decir que estamos asistiendo al desarrollo de una vista judicial oficial; sin embargo las palabras pronunciadas por los personajes intervinientes y la manera de narrar Livio los acontecimientos dan a la escena apariencia judicial. Tanto el discurso de acusación de Perseo como el de defensa de Demetrio observan los preceptos fijados en los tratados clásicos de retórica que regulan la construcción de esta clase de discursos. Si se examina el texto acotado desde el punto de vista del léxico, del contenido, de la estructura y de los múltiples y variados recursos retóricos utilizados por Livio, se puede decir, con razón, que estamos ante dos muestras claras de discurso forense que hacen del paduano un verdadero orador y que, en algunos aspectos, recuerdan la oratoria ciceroniana y sacan a la luz los estrechos vínculos entre la retórica y 
la historiografía. La presencia de términos específicos del lenguaje jurídico como crimen, criminari, dicere causam, argumentari, accusare, accusator, defendere, defensio, iudex, aduocatus, patronus, parricidium, innocens y muchos otros indican que nos hallamos, sin duda, ante una muestra de genus iudiciale.

Livio, dejando ya a un lado las palabras pronunciadas por el atribulado padre, desarrolla una causa judicial de ficción dividida en las dos fases tradicionales de un proceso forense - la acusación y la defensa-, fases ambas desarrolladas explícitamente y por separado en el fragmento objeto de consideración, a diferencia de lo que es habitual en las causas judiciales comprendidas en la oratoria ciceroniana, en donde el orador se ocupa, a juzgar por el texto que nos ha llegado, o bien de la acusación (In... oratio) o, sobre todo, de la defensa (Pro... oratio).

Buen conocedor de la teoría retórica, el historiador Livio construye, en primer lugar, un discurso de acusación que, desde el punto de vista del contenido y, consecuentemente, del léxico, ha de incluirse dentro de las causas de tipo forense. Empieza, de acuerdo con el orden natural fijado en la retórica, por la acusación. No puede haber refutación ni réplica, si previamente no ha habido acusación explícita o velada. El propio Cicerón, en el exordio del discurso en defensa de P. Quincio, se queja de que, por la injusticia del pretor, se ve obligado a defender la causa de su cliente antes de escuchar la palabra del acusador y a «parar los golpes y sanar las heridas [...] cuando todavía el enemigo no ha disparado un solo dardo» (Quinct. 8). El «orador» Livio, en la disposición de las dos intervenciones, respeta el orden natural defendido por los tratadistas de retórica. Los dos discursos tienen en común, como rasgo distintivo, el hecho de que, aunque Filipo ejerce de juez encargado de emitir el veredicto, sin embargo ni el acusador Perseo ni el acusado Demetrio se dirigen jamás a él, como al juez de la causa, sino al padre y, alternativamente, al hermano, pero nunca al juez, como es normal en el discurso judicial grecolatino. Ha de exceptuarse de esta constante un pasaje del discurso de Demetrio, en la peroratio, en donde, con un tono apasionado y suplicante, menciona al "padre juez»: Quid mihi spei esset, nisi patrem iudicem haberem? (40, 15, 15). Con excepción de este pasaje, la norma es que acusador y acusado se dirijan al «padre» por medio del vocativo pater (Perseo, en siete ocasiones ${ }^{8}$, y Demetrio, en tres ${ }^{9}$ ), alternando una sola vez con frater, cuando el que habla es Perseo $(40,9,8)$ y con el vocativo Perseu, si es Demetrio el que replica a su hermano ${ }^{10}$.

Las palabras de suave reconvención de Filipo a sus hijos, mezcladas con un sentimiento de profunda pena, se van transformando, en el artístico relato de Livio, en palabras de reproche y de rabia que, pasando por fases distintas, indicadas cada una de ellas por la sucesión de frases cortas, en construcción paratáctica, alcanzan el punto más emotivo en la repetición retórica de cuatro imperativos (Walsh 1963, 234) destacados, además, por la fuerza significativa que les confiere el hecho de estar colocados en la posición inicial de la frase:

[...] nec fratrem nec patrem potestis pati. Nihil cari, nibil sancti est. In omnium uicem regni unius insatiabilis amor successit. Agite, conscelerate aures paternas, decernite criminibus, mox ferro decreturi, dicite palam quidquid aut ueri potestis aut libet comminisci; resertae aures sunt, quae posthac secretis alterius ab altero criminibus claudentur $(40,8,19-20)$.

8 40, 9, 11: Credis me, pater, inter inermes conuiuas cenaturum fuisse, ad quem armati comissatum uenerunt? Otros pasajes los encontramos en: 40, 11, 13; 40, 10, 1; $40,10,5 ; 4010,10 ; 40,11,4 ; 40,11,10$.
9 40, 12, 3: Omnia, quae reorum antea fuerant auxilia, pater, praeoccupauit accusator. Véanse los otros dos ejemplos en: 40, 15, 4 y 40, 15, 9.

${ }^{10}$ Liv. 40, 12, 9: Oportuit autem, Perseu, si proditor ego patris regnique eram, si... 


\section{Discurso de Perseo}

El conocimiento de la preceptiva retórica por parte de Livio y su habilidad para organizar la totalidad de la obra queda de manifiesto si se considera su relato desde el punto de vista del conjunto. Las sucesivas unidades menores que conforman la narración están perfectamente engarzadas entre sí e integradas en el todo por medio de diferentes recursos de naturaleza léxica o estructural que sirven para articular el relato. Las transitiones o transitus tienen la función de facilitar el paso de una escena a otra de manera gradual, no brusca, como sucede antes de los discursos de Perseo: Haec furens ira cum dixisset, lacrimae omnibus obortae, et diu maestum silentium tenuit. Tum Perseus...(40, 8, 20), y de Demetrio: Postquam dicendi finem Perseus fecit, coniecti eorum, qui aderant, oculi in Demetrium sunt, uelut confestim responsurus esset. Deinde diu silentium fuit, cum perfusum fletu appareret omnibus loqui non posse. Tandem uicit dolorem ipsa necessitas, cum dicere iuberent, atque ita orsus est $(40,12,1-2)$.

En la intervención de Perseo se diferencian con claridad las cuatro partes canónicas de una oratio judicial: las dos informativas (la narratio y la argumentatio) y las dos emotivas o pasionales (el exordium y la peroratio final).

Para el exordio de su discurso de acusación, Perseo elige la modalidad de la captatio a partir de la propia persona. Con la queja de que su padre, que no lo tiene por un verdadero hijo, sino por hijo de una concubina, le da un trato discriminatorio, adopta el papel de víctima con el objetivo de predisponer favorablemente al padre/juez y despertar el atento interés por lo que le va a decir. El tono irónico que envuelven sus primeras palabras ( $\mathrm{O}$ sea que anoche debía haber abierto la puerta, dejando entrar a los convidados armados y presentado mi cuello a la espada...») recuerda un pasaje del discurso de Cicerón en defensa de Milón en el que, con el mismo tono irónico, dice a los jueces que hubiera sido preferible para Milón entregar su cuello a Clodio [...] antes que ser degollado legalmente por ellos por no haberse entregado a aquel para que lo degollara. La semejanza de ambos pasajes, por el tono irónico empleado, por su contenido, por el empleo del indicativo con valor modal e, incluso, por el léxico, es evidente, y pone de manifiesto que el estilo oratorio de Livio no se halla muy alejado del de Cicerón ${ }^{11}$.

Una vez finalizado el exordio, relata Livio las circunstancias que rodearon el intento de asesinato de Demetrio, con la particularidad de que no existen fórmulas de transición que marquen el paso de la narración a la argumentación y, además, las partes informativa y probatoria no funcionan como unidades independientes. La narratio se entremezcla con la probatio. A cada uno de los puntos de la acusación de Perseo le sigue la demostración con el fin de hacer verosímil, si no verdadero, el hecho imputado.

Tres son las acusaciones (crimina) fundamentales que dirige Perseo contra Demetrio: a) la de haber querido asesinarlo; b) la de aspirar al trono; c) la de connivencia y complicidad con los romanos y la consiguiente traición a su padre y a su pueblo. Las tres imputaciones van unidas entre sí por una relación de causalidad, de manera especial la de que Demetrio había querido asesinarlo, desarrollada en la primera parte de la intervención de Perseo. Pero, ¿Por qué había de querer Demetrio eliminar a su hermano mayor? La razón la da el propio Perseo cuando, cambiando de destinatario, se dirige a Demetrio y le revela el móvil del plan urdido: "Quieres reinar a toda costa» (Regnare utique uis) y yo soy un obstáculo en el camino de tus ambiciones: huic

11 Cic. Mil. 31: certe optabilius fuit Miloni dare iugulum P. Clodio [...], quam iugulari a uobis, quia se non iugulandum illi tradidisset. Cf. Liv. 40, 9, 1: aperienda nimirum nocte ianua fuit [...], praebendumque ferro iugulum, quando non creditur... 
spei tuae — dice Perseo a Demetrio- obstat aetas mea, obstat gentium ius, obstat uetustus Macedoniae mos, obstat uero etiam patris iudicium $(40,9,8)$. La relación de causalidad entre las dos acciones parece incontestable y, como prueba de la solidez del argumento, vuelve a mencionarlo en la conclusión, dirigiéndose ahora al padre, no al hermano, como antes: Cupit regnum, et quidem scelerate cupit, qui transcendere festinat ordinem aetatis, naturae, moris Macedonum, iuris gentium $(40,11,7)$.

Por otra parte, la acusación de Perseo de que Demetrio quiso matarlo la noche anterior pertenece al estado de causa «conjetural» que se sustenta en más de un indicio que la hacen verosímil y que Livio introduce en el relato mediante la secuencia de tres preguntas, dispuestas anafóricamente y dirigidas al presunto asesino frustrado, en las que se alude a las tres circunstancias siguientes: la «noche», la «enemistad», la compañía de jóvenes «armados de espadas»: Quid hoc noctis, quid inimicus ad iratum, quid cum ferro succinctis iumenibus uenis? (40, 9, 12).

El tercer punto de la acusación contra Demetrio es el de la connivencia y complicidad con los romanos y, en consecuencia, la de traición a su pueblo y a su padre. Manifiesta que los romanos y todas las ciudades liberadas están de parte de Demetrio y, en un intento de suscitar los celos de Filipo, afirma que, para Demetrio, el romano Tito Quincio es mentor y maestro en todo, hasta el extremo de que Demetrio ha renegado de Filipo como padre y ha puesto a T. Quincio en su lugar. Entre otras maledicencias, añade que «solo Demetrio lo es todo para los romanos, lo llaman ya rey cuando aún está vivo su padre»: Demetrius iis unus omnia est, eum iam regem patre uiuo appellant $(40,11,4)$.

Tras la exposición y la prueba de la acusación de Perseo, se cierra el discurso apelando, con tono suplicante, a la clemencia y a la justicia del padre (Qui occisurus fratrem fuit, habeat etiam iratos paternos deos; qui periturus fraterno scelere fuit, perfugium in patris misericordia et iustitia habeat: $40,10,2)$, pues — se pregunta Perseo- «¿en qué otro sitio voy a refugiarme?»o, valiéndose de una reflexión deliberativa: Quo me conferam?

El discurso se cierra con unas palabras de Perseo destinadas a despertar la indignatio en contra de Demetrio, a quien su ciega ambición de reinar no le impide «saltarse el orden de la edad, de la naturaleza, de la tradición macedónica, del derecho de los pueblos $(40,11,7)$, y si el hermano mayor, a quien corresponde el trono por derecho y por voluntad paterna, constituye un obstáculo, "quítesele de en medio: no será el primero que llega al trono por la vía de la muerte de su hermano", concluye $(40,11,7-8)$.

\section{Discurso de Demetrio}

La maestría demostrada por Livio en la elaboración retórica del discurso de Perseo se repite en la intervención de autodefensa de Demetrio, reflejo, punto por punto, de las palabras acusatorias de Perseo. La estructura es la misma y, puestos a encontrar alguna diferencia, habría que señalar que la captatio, en la refutación de Demetrio, se busca a partir de la persona del adversario ( $a b$ aduersarii persona), no a propria persona, como sucede en el discurso de Perseo: «El acusador, padre, ha utilizado todos los medios de defensa que antes tenían los acusados» (Omnia, quae reorum antea fuerant auxilia, pater, praeoccupauit accusator: 40, 12, 3). Las fingidas lágrimas de Perseo hicieron sospechosas las lágrimas sinceras del acusado, juego de palabras que, iluminado por la antítesis simulatis lacrimis-ueras lacrimas, anuncia el camino por el que va a transitar Demetrio en su defensa: la inconsistencia de la acusación de Perseo por estar basada en patrańas inventadas y en argumentos falaces y amańados: hoc ficto et composito argumento $(40,12,7)$. En la brillante refutación de Demetrio tiene menos peso, como era de esperar, la narratio que la argumentatio. El histo- 
riador concede más importancia al bloque argumentativo tanto por la mayor extensión que le dedica como por la exhaustividad con la que se desarrollan las pruebas presentadas en contra de la acusación de Perseo.

Las tres principales imputaciones —intento de asesinato, ambición de poder, traición y connivencia con los romanos- son destruidas retóricamente por procedimientos varios. La acusación de intento de asesinato la refuta Demetrio invocando varios de los denominados en retórica «atributos de los hechos» (Cic. inu. I, 26, 37-39), como las circunstancias de tiempo y lugar, nada propicias para llevar a cabo el fratricidio: Dies qualis? «Qué clase de día era? El de unas maniobras militares, el de un banquete, el de un festín [...]. El día en que fue purificado el ejército...» $(40,13,3)$. Igualmente desfavorable era el lugar donde, presuntamente, pensaban cometer el asesinato: en la casa de Perseo. La eficacia de la refutación se rearma con la recurrencia de interrogaciones retóricas acumuladas, tan presentes en la oratoria ciceroniana, sobre todo en los pasajes emotivos y vehementes. Pide Demetrio que comparezcan los hombres que empuñaron la espada y que, como si del locus testium se tratara, declaren si iban armados para matar a Perseo, instigados por Demetrio y siendo él sabedor, o si, más bien, iban armados para su propia defensa. Pide también, como refutación de la acusación de Perseo, que éste explique si el ataque iba a producirse abiertamente o a escondidas:

«Si abiertamente, ¿por qué no íbamos todos armados? ¿Por qué solo tenían armas aquellos que maltrataron a tu espía? Si a escondidas, ¿cuáles eran los pasos del plan? Cuando yo me hubiera despedido como invitado, una vez finalizado el festín, ¿se habrían quedado los cuatro para atacarte cuando estuvieras dormido? ¿Cómo habrían pasado desapercibidos si no eran de la casa, si eran de los míos y, además, especialmente sospechosos porque antes habían intervenido en una reyerta? Por otra parte, ¿cómo pensaban escapar después de matarte? ¿Con cuatro espadas era posible tomar por asalto tu casa?» $(40,14,10-11)$.

Respecto de la tercera alegación de Perseo - la connivencia con los romanos y la traición a su padre - replica al hermano, no al padre, que, de haber sido eso cierto, debería haberlo acusado antes de traición y no esperar a lo ocurrido la noche anterior. Además, a qué venía la acusación de haber querido eliminarlo para ocupar su lugar, porque, si los romanos tenían tanta influencia como para imponer a Macedonia el rey que ellos quisieran y si era tan grande su ascendiente entre los romanos, ¿qué necesidad había de cometer un asesinato? Por otra parte, se defiende de la relación de amistad con los romanos diciendo a su padre que convierte «en acusación lo que debería ser motivo de gloria», pues él no pidió «ser entregado a los romanos como rehén ni ser enviado a Roma como embajador. Cuando tú me enviaste - le dice- no me negué a ir [...]. Por consiguiente, padre, tú fuiste la causa de mi amistad con los romanos» $(4015,5-7)$.

Los sucesivos argumentos que, en forma de silogismos retóricos construidos a base de premisas y conclusiones explícitas o veladas, sirven a Demetrio para echar por tierra las acusaciones de Perseo, resultan más eficaces por la cuidada y estudiada selección del léxico, sobre todo del que hace referencia a la idea de «invención» y «ficción» de las acusaciones que Perseo dirige contra Demetrio. Livio pone en boca del hijo menor de Filipo palabras que restan fuerza a la acusación de Perseo, tales como argumentum, definido en retórica como narratio rei fictae (Rhet. Her. I, 8, 13), pero verosímil, marcado, además, por los determinantes fictum y compositum: nocturno hoc ficto et composito argumento $(40,12,7)$. En la misma línea está la palabra fabula, denominación dada en los tratados de retórica a los relatos de ficción que no son ni verdaderos ni verosímiles (Rhet. Her. I, 8, 13). Con la elección del término fabula («relato legendario») para calificar los hechos ocurridos la 
noche anterior, se está negando no solo la veracidad de los mismos sino incluso su verosimilitud y, en consecuencia, pierden toda credibilidad: non exspectatam fabulam esse noctis huius $(40,12,9)$ y Quin tu, omissa ista nocturna fabula, ad id quod doles [...] reuerteris? $(40,15,2)$.

Mientras que en el discurso de Perseo la peroración final busca suscitar la indignación contra Demetrio, en el de autodefensa de Demetrio el sentimiento que se quiere despertar es el de la commiseratio, función propia de la peroración de un discurso de defensa. Lamenta Demetrio que, por no disponer de asesores ni de abogados, se haya visto obligado a ejercer él su propia defensa a pesar de la falta de tiempo para preparar convenientemente la causa (Walsh, 1963, 226-227). Esta es la razón por la que deposita todas las esperanzas de salvación en su padre y juez, y concluye con la petición característica de la peroratio de una causa judicial: «Te suplico, pues, que me salves» $(40,15,2)$. El relato de Livio está dominado por «una brillante orquestación retórico-dramática en la que la tensión y los sentimientos humanos desempeñan prioritario papel» (Moreno 2008, 327).

La sólida armazón argumentativa de los dos discursos está revestida por el brillo literario propio de la oratoria forense, brillo que le confiere la presencia de un sinfín de recursos de diversa naturaleza lingüística, acumulados a veces, como sucede en Quid hoc noctis, quid inimicus ad iratum, quid cum ferro succinctis iuuenibus uenis? $(40,9,12)$, expresión en la que la convergencia de distintas figuras (la interrogación retórica, la anáfora, el asíndeton, la disposición de miembros crecientes y la distribución tripartita, de la que tanto gusta Livio) añade fuerza probatoria a la suma de los indicios de nocturnidad, enemistad y al hecho de que Demetrio, en palabras de Perseo, fuera acompañado por jóvenes armados. En el texto se produce una significativa concentración de diferentes elementos de ornato, sobre todo en los pasajes más cargados de emoción, que, a la vez que embellecen la prosa literaria de Livio, contribuyen a dar verosimilitud al contenido. Sería muy larga y no aportaría nada sustancial al relato la relación completa de los recursos seleccionados por Livio.

Que los discursos de Perseo y de Demetrio constituyen dos muestras de orationes judiciales insertas en el relato historiográfico de Livio parece estar fuera de duda. La selección de un léxico especializado, la disposición de las partes canónicas de una oratio, la concentración de múltiples configuraciones literarias, medio de embellecer sobre todo las partes pasionales de un discurso, sustentan la opinión de que las normas retóricas, válidas, en un primer momento, solo para el género de la oratoria, regulan también la construcción de los frecuentes parlamentos que los historiadores insertan en sus relatos, tanto en las arengas de corte deliberativo como en los pocos discursos judiciales que, como el estudiado de Tito Livio, encontramos en obras clasificadas dentro del género historiográfico.

La ficción judicial no se cierra con el pronunciamiento de la sentencia. El proceso queda abierto, pendiente de un veredicto que, según anuncia Filipo, ha de sustentarse no en los hechos concretos acaecidos en la noche anterior, sino en la observación continuada del comportamiento posterior de los hijos entre sí y con su padre. En cualquier caso, la sentencia, la dura sentencia, la ha de dictar el tiempo, y la pena infligida será el remordimiento del padre-juez por haber consentido la muerte, por envenenamiento, de su hijo Demetrio. Al abatimiento y añoranza de Filipo por la pérdida de su hijo se añadían los remordimientos por su propia crueldad y, a pesar de haberlo intentado de múltiples maneras, no pudo impedir que el culpable Perseo disfrutase, al final, del premio de su delito. El peso de la sentencia, no pronunciada en el momento de la finalización de la vista judicial, cayó, en definitiva, sobre el padre-juez, que no supo ver, cuando correspondía, cuáles eran los verdaderos móviles del acusador o se dejó engañar, interesadamente, por las palabras de quien iba a salir beneficiado. 
Para Tito Livio, la culpa es toda de Filipo que no supo ser ni buen padre, ni buen rey, ni buen político. El que debía dictar, como justo juez, la sentencia es el sentenciado que, por su error, paga la culpa de su delito de ceguera e inacción. La victoria de Perseo en el debate dialéctico es causa de la división y destrucción del reino de Macedonia.

\section{BiBLIOGRAFÍA}

Bornecque, H., 1933, Tite-Live, Paris: Boivin \& Cie.

Briscoe, J., 2008, A Commentary on Livy books 38-40, Oxford: University Press.

Burk, E., 1971, «The Third Decade», en: T. A. Dorey, (ed.), Livy, London: Routledge \& Kegan Paul.

Cantó Llorca, M.a J., Codoñer, C., Ramos Guerreira, A., 1987, «Oratoria», en: C. Codoñer (ed.), Géneros literarios latinos, Salamanca: Ediciones Universidad Salamanca, 13-37.

Chaplin, J. D., 2000, Livy's Exemplary History, Oxford: University Press.

Cocchia, E., 1980, Tito Livio e Polibio, Roma: Studio Bibliografico Adelmo Polla.

Cogitore, I. et Ferretti, G., 2014, «L'histoire face à la rhétorique: un défi à relever. Présentation», Exercices de rhétorique, 3, 1-6.

Feldherr, A., 1998, Spectacle and Society in Livy's History, Berkeley: University of California Press.

Girod, M. R., 1979, «Rhétorique et Histoire chez Tite-Live», en: R. Chevalier (ed.), Colloque sur la Rhétorique. Caliope I, Paris: Les Belles Lettres, 61-70.

Gries, K., 1949, «Livy's Use of Dramatic Speech», The American Journal of Philology 70, 118-141.

Hinojo, G., 1985, "La historia como género literario: opus...unum hoc oratorium maxime», en: VII Simposi d'Estudis Clàssics. Sitges 1983, Barcelona, 191-198.

Iglesias Zoido, J. C., 2008, Retórica e Historiografía. El discurso militar en la Historiografía desde la Antigüedad hasta el Renacimiento, Madrid: Ediciones Clásicas.

Lausberg, H., 1966, Manual de Retórica Literaria. t. I. Madrid: Editorial Gredos.

Luce, T. J., 1977, Livy. The Composition of His History, Princeton: Princeton University Press.

Mal-Maeder, D. van, 2007, La fiction des déclamations, Leiden; Boston: Brill.

Marincola, J., 2007, «Speeches in Classical Historiography», en: J. Marincola (ed.), A Companion to Greek and Roman Historiography, vol. I. Oxford: Blackwell Publishing, 118-132.

Marouzeau, J., 1921, "Pour mieux comprendre les textes latins, (essai sur la distinction des styles)», $R P h$ 45, 149-193.

Miller, N. P., 1975, «Dramatic Speech in the Roman Historians», Greece \& Rome 23, 45-57.

Moreno, I., 2008, «La arenga de Marco Claudio Marcelo en Canusio (T.L. 27.13)», en: J.C. Iglesias Zoido (ed.), Retórica e Historiografía. El discurso militar en la Historiografía desde la Antigüedad hasta el Renacimiento, Madrid: Ediciones Clásicas, 319-40.

Pianezzola, E., 1969, Traduzzione e ideologia. Livio interprete di Polibio, Bologna: Casa Editrice Prof. Riccardo Patron.

SÁNChez SAlor, E., 2008, «Retórica e Historiografía en Roma», en: J.C. Iglesias Zoido (ed.), Retórica e Historiografía. El discurso militar en la Historiografia desde la Antigüedad hasta el Renacimiento, Madrid: Ediciones Clásicas, 125-142.

Ullmann, R., 1927, La technique des discours dans Salluste, Tite-Live et Tacite, Oslo: J. Dybwad.

Velasco, M., 2000 «El paradigma como prueba retórica en los discursos judiciales», AGORA Vol. 19, n. ${ }^{\circ} 1,31-58$.

Villalba Álvarez, J., 2008, «Épica e historiografía: la arenga militar en los Punica de Silio Itálico y su relación con Tito Livio», en: J.C. Iglesias Zoido (ed.), Retórica e Historiografía. El discurso militar en la Historiografía desde la Antigüedad hasta el Renacimiento, Madrid: Ediciones Clásicas, 341-366.

Walsh, P. G., 1963, Livy, his historical aims and methods, Cambridge: University Press.

Woodman, A. J., 1988, Rhetoric in Classical Historiography. Four Studies, London / Sidney: Routledge. 